\title{
Patient versus parental perceptions about pain and disability in children and adolescents with a variety of chronic pain conditions
}

\author{
Thomas R Vetter MD MPH${ }^{1}$, Cynthia L Bridgewater BSN MSN², Lee I Ascherman MD MPH ${ }^{1}$, \\ Avi Madan-Swain $\mathrm{PhD}^{1}$, Gerald L McGwin Jr MS PhD ${ }^{1}$
}

TR Vetter, CL Bridgewater, LI Ascherman, A Madan-Swain, GL McGwin Jr. Patient versus parental perceptions about pain and disability in children and adolescents with a variety of chronic pain conditions. Pain Res Manag 2014;19(1):7-14.

BACKGROUND: Cross-informant variance is often observed in patient self-reports versus parent proxy reports of pediatric chronic pain and disability.

OBJECTIVE: To assess the relationship and merit of the child versus parent perspective.

METHODS: A total of 99 patients (eight to 17 years of age [mean 13.2 years]; $71 \%$ female, $81 \%$ Caucasian) and parents completed the Pediatric Pain Questionnaire and Functional Disability Inventory at their initial clinic visit. Patients' and parents' pain intensity and disability scores were analyzed using an intraclass correlation coefficient (ICC), Wilcoxon signed-rank test, Bland-Altman plot and Spearman's correlation coefficient. The association between clinical/demographic variables and differences in patient/parent pain intensity and disability scores was assessed using multivariable regression.

RESULTS: There was significant agreement between patients' self-reports and parents' proxy reports of their child's pain intensity (ICC $=0.52$; $\mathrm{P}<0.001)$ and disability $(\mathrm{ICC}=0.57 ; \mathrm{P}=0.004)$ at the individual level. There were no significant group differences in patient versus parent-proxy pain intensity scores $(\mathrm{P}=0.40)$ and disability scores $(\mathrm{P}=0.54)$. The difference between patient and parent-proxy pain intensity was associated with patients' self-reported pain intensity $(\mathrm{P}<0.001)$. The difference between patient and parent-proxy disability was associated with patient's selfreported pain disability $(\mathrm{P}<0.001)$. Bland-Altman plots revealed major inter-rater variation in the Pediatric Pain Questionnaire and Functional Disability Inventory across their score ranges. A significant relationship $(r=0.38 ; \mathrm{P}<0.001)$ was observed between patients' self-reported pain intensity and disability.

CONCLUSIONS: While equal merit should ideally be given to pediatric chronic pain patients' self-reports and their parents' proxy reports of pain intensity and disability, it would appear that, as needed, pediatric patients or parents can offer a clinically valid, single clinical perspective.

Key Words: Adolescents; Children; Chronic pain; Disability; Functional capacity; Pain intensity; Parent-child; Pediatrics

Dediatric chronic pain has a detrimental effect on the health of youth, with a concomitant adverse impact on all individuals invested in their well-being, paticularly their parents (1-5). Chronic pain also often impacts children's daily activities; therefore, accurately assessing the child's difficulty in performing usual activities is important (6-8). Pain intensity and functional disability are, thus, both routinely incorporated into the clinical assessment of pediatric chronic pain patients (9-11). However, there may appear to be a disconnect between reported pediatric pain intensity and its related level of functional disability or impairment $(9,12)$.
Les perceptions des patients et des parents sur la douleur et l'incapacité chez les enfants et les adolescents atteints de diverses maladies chroniques

HISTORIQUE : On observe des variances transversales dans les rapports des patients et des parents mandataires sur la douleur et l'incapacité chronique en pédiatrie.

OBJECTIF : Évaluer la relation entre le point de vue de l'enfant et celui du parent et le mérite des deux points de vue.

MÉTHODOLOGIE : Au total, 99 patients (de huit à 17 ans [moyenne de 13,2 ans]; $71 \%$ de filles, $81 \%$ de blancs) et parents ont rempli le questionnaire sur la douleur en pédiatrie et l'inventaire de l'incapacité fonctionnelle lors de leur premier rendez-vous en clinique. Les chercheurs ont analysé les indices d'intensité de la douleur et d'incapacité chez les patients et les parents au moyen d'un coefficient de corrélation intraclasse (CCI), du test de comparaison des données de Wilcoxon, du graphique de BlandAltman et du coefficient de corrélation de Spearman. Ils ont évalué l'association entre les variables cliniques et démographiques et les différences d'indices d'intensité de la douleur et d'incapacité chez les patients et les parents à l'aide de la régression multivariable.

RÉSULTATS : Les chercheurs ont constaté une concordance significative entre les rapports des patients et ceux des parents mandataires au sujet de l'intensité de la douleur des enfants $(\mathrm{CCI}=0,52 ; \mathrm{P}<0,001)$ et de leur incapacité $(\mathrm{CCI}=0,57 ; \mathrm{P}=0,004)$ sur le plan individuel. Ils n'ont pas remarqué de différences significatives de groupe pour ce qui est des indices d'intensité de la douleur $(\mathrm{P}=0,40)$ et d'invalidité $(\mathrm{P}=0,54)$ entre les patients et les parents mandataires. La différence d'intensité de la douleur entre les patients et les parents mandataires s'associait à l'intensité de la douleur déclaré par les patients $(\mathrm{P}<0,001)$. La différence entre l'incapacité déclarée par le patient et par le parent mandataire s'associait à l'incapacité découlant de la douleur déclarée par le patient $(\mathrm{P}<0,001)$. Les graphiques de Bland-Altman ont révélé une variation marquée entre les évaluateurs pour ce qui est de la plage des indices du questionnaire de douleur en pédiatrie et de l'inventaire d'incapacité fonctionnelle. Les chercheurs ont constaté une relation significative $(r=0,38 ; \mathrm{P}<0,001)$ entre l'intensité de la douleur et l'incapacité déclarées par le patient.

CONCLUSIONS : Idéalement, il faudrait attribuer le même mérite au compte rendu des patients atteints de douleur chronique et à celui de leurs parents mandataires au sujet de l'intensité de la douleur et de l'incapacité, mais il semble qu'au besoin, les patients d'âge pédiatrique ou leurs parents peuvent donner un point de vue unique valable sur le plan clinique.

Given the integral role of parents in their children's lives, parents and patients often each provide reports of the patient's pain intensity and pain-related functioning (8). However, cross-informant variance is often observed in patient self-reports versus parent proxy reports of pediatric chronic pain and disability. The integrative model of pediatric chronic pain, proposed by Palermo and Chambers (13), as well as the biobehavioural model of pediatric chronic pain proposed by Varni et al (14), include biological, parental and environmental contributing factors, in addition to a strong interactive element in the parent-child dyad. Published data show that parental chronic

${ }^{1}$ University of Alabama at Birmingham; ' Children's Hospital of Alabama, Birmingham, Alabama, USA

Correspondence: Dr Thomas R Vetter, Department of Anesthesiology, University of Alabama School of Medicine, JT862,

619 19th Street South, Birmingham, Alabama 35249-6810, USA. Telephone 205-934-6501, fax 205-996-7272, e-mail tvetter@uab.edu 


TABLE 1
Measurement instruments completed by study patients
and their parents
\begin{tabular}{lcc} 
Measurement instrument & Patient completed & Parent completed \\
\hline Pediatric Pain Questionnaire & Patient self-reported & Parent proxy-reported \\
Functional Disability Inventory & Patient self-reported & Parent proxy-reported \\
Brief Pain Inventory-Short Form & - & Parent self-reported \\
Pain intensity component & - & Parent self-reported \\
Pain interference component & - & Parent self-reported \\
\hline
\end{tabular}

pain is associated with chronic pain in older children and adolescents (15-18). It is, thus, plausible that such factors, including parental chronic pain intensity, could affect agreement within the parent-child dyad with regard to a pediatric patient's chronic pain and related disability.

Children with chronic pain also typically interact with numerous health care providers during their search to understand and to ameliorate their pain (19). Such interactions with health care providers have a tremendous influence on children's perceptions and chronic pain experiences. However, in these clinical interactions, children have reported feeling misunderstood, disbelieved and abandoned (19). This may result, in part, from the unique central role of the parent and the nearly certain presence of a parent when pediatric health care services are provided (20). This often central, if not predominant, role of the parent is exemplified by seeking care, treatment expectations and clinical decision making often relying equally or even solely on parent proxy reports of a pediatric patient's health status, including chronic pain intensity and pain-related disability $(21,22)$

Therefore, to make the best use of clinical data provided by both the patient and parent, clinicians need to be aware of patterns of agreement versus disagreement in these two perspectives (8). Previous studies have observed statistically significant correlation coefficients between child- and parent-reported scores when validating the Functional Disability Inventory (FDI) (23), the Child Activity Limitations Interview (CALI) $(7,24)$ and the Child Activity Limitations Questionnaire (25). However, the reported correlation coefficients varied widely between 0.21 and $0.73(7,23-25)$. These authors also reported only moderate correlation coefficients $(0.37$ to 0.43 ) between pediatric chronic pain patients' self-reported pain intensity and their pain-related functional disability or impairment $(7,24,25)$. Thus, there appears to be a need for further evaluation of the complex relationship in the parent-child dyad with pediatric chronic pain.

The present prospective study was, therefore, undertaken to further examine the relationship in the parent-child dyad between pain and disability in pediatric patients with a variety of chronic pain disorders, who were referred to a pediatric chronic pain medicine program. Specifically, using collected primary data, we assessed: the agreement between pediatric patients' self-report and their parents' proxy report of the child's chronic pain intensity using the Pediatric Pain Questionnaire (PPQ) and functional disability using the FDI; the degree to which this patient-parent agreement is affected by additional demographic, clinical and environmental factors including the parents' own self-reported pain intensity and disability using the Brief Pain Inventory-Short Form (BPI-SF); and the relationship between pediatric patients' self-reports of their chronic pain and functional disability.

\section{METHODS}

Setting and participants

Study participation was offered to 145 eligible patients between eight and 17 years of age, who were consecutively evaluated in an outpatient pediatric chronic pain medicine clinic at a free-standing children's hospital (the Children's Hospital of Alabama, Birmingham, Alabama, USA) between May 2009 and December 2010. All patients were referred to this ambulatory clinic (by their primary care physician or another subspecialist physician) with an existing chronic pain diagnosis. The present study was approved by the Institutional Review Board of the University of Alabama at Birmingham, Birmingham, Alabama. Written parental consent and written patient assent were obtained before study enrollment.

Because of the low prevalence in the study population of patients of Hispanic or Latino origin $(3.2 \%)$ and a primary language other than English (3.2\%) (26), patients in whose families English was not the primary language were excluded from the present study. Patients with severe cognitive dysfunction were also excluded.

\section{Study design}

Enrolled patients and their parents completed the study questionnaires, diagnostic instruments and health surveys (Table 1) at the time of their initial appointment in the clinic, but before being evaluated by a pain medicine physician or any other health care providers. The patient and the parent were consistently instructed by the study coordinator on how to complete the measurement instruments. The patient and parent were explicitly instructed to complete the study questionnaires entirely independently to minimize any respondent cross-contamination. The study instruments were administered in the same order.

\section{Patient measurement instruments}

Pain intensity - PPQ: The PPQ is a patient self-reported and agespecific (child: eight to 12 years of age; adolescent: 13 to 18 years of age) assessment instrument $(9,12,27)$. Parent proxy reports are also available for each age group. The PPQ assesses pain intensity using a $100 \mathrm{~mm}$ horizontal line (visual analogue scale [VAS]) that is without numbers but ranges from 0 (anchored either by a smiling cartoon face and "no hurt at all" or by "no pain, not hurting, no discomfort") to 100 (anchored either by a sad cartoon face and "hurting a whole lot" or by "severe pain, hurting a whole lot, very uncomfortable"). The $\mathrm{PPQ}$ assesses pain intensity at the present time ("now") and at its worst in the past week. In the absence of clear published guidance, the PPQ pain intensity score at its worst in the past week was used because these levels were the likely motivation for seeking care in the clinic. No other sensory or affective elements of the PPQ were used in the present study. The patient completed the age-specific self-report version of the PPQ, and the parent completed the parent proxy-report PPQ.

The PPQ is a reliable and valid tool for measuring pediatric chronic pain intensity $(9,27)$. An evidence-based review of the various assessment tools for pediatric pain, including pain intensity self-report scales, rated the VAS and PPQ as "well established" (28). The PPQ has been one of the most widely used comprehensive pain questionnaire for children and adolescents with chronic pain disorders (29).

Disability and functional impairment - FDI: The FDI is a parallel patient self-report and parent proxy-report questionnaire for children and adolescents (eight to 17 years of age) that assesses perceived difficulty in performing activities in the context of school, home, recreation and social interaction $(11,30)$. The FDI consists of 15 items that are each rated on a five-point scale $(0=$ no trouble, $1=$ a little trouble, $2=$ some trouble, $3=$ a lot of trouble, $4=$ impossible), generating a total score ranging from 0 to 60 . The patient completed the FDI Child and Adolescent Form, and the parent completed the FDI Parent Form.

The FDI has demonstrated sufficient reliability and validity in assessing disability across the range of chronic pain conditions (23). Based on published psychometric properties, a recent evidence-based review classified the FDI as "well established" (31). Of note, a recent multicentre study validated a three-level ordinal classification system for the FDI ( 0 to $12=$ 'no/minimal', 13 to $29=$ 'moderate' and $>30=$ 'severe'), with patients scoring in the 'moderate' disability category being the most typical patients presenting to specialty pediatric pain medicine clinics (32). However, the raw total (0 to 60) FDI score was used for the present analyses. 
TABLE 2

Correlations between patient self-reported and parent proxy-reported pain intensity scores on the Pediatric Pain Questionnaire (PPQ) and functional disability scores on the Functional Disability Index (FDI)

\begin{tabular}{|c|c|c|c|}
\hline \multirow[b]{2}{*}{ Scale } & \multicolumn{3}{|c|}{ Intraclass correlation coefficients } \\
\hline & Total sample $(n=98)$ & $8-12$ years of age $(n=37)$ & $13-17$ years of age $(n=61)$ \\
\hline PPQ (visual analogue scale) & $0.52(0.36 \text { to } 0.65)^{*}$ & $0.15(-0.18 \text { to } 0.45)^{\dagger}$ & $0.75(0.62 \text { to } 0.84)^{*}$ \\
\hline FDI & $0.57(0.41 \text { to } 0.69)^{*}$ & $0.43(0.13 \text { to } 0.66)^{\ddagger}$ & $0.66(0.49 \text { to } 0.78)^{*}$ \\
\hline
\end{tabular}

Numbers in parentheses represent the $95 \% \mathrm{Cls}$ for reported point estimates. ${ }^{*} P<0.001$ (patient versus parent); $P=0.18$ (patient versus parent); $¥ P=0.004$ (patient versus parent)

\section{Parent measurement instrument}

Parent chronic pain intensity - BPI-SF: The BPI-SF is a selfadministered questionnaire that assesses the severity of adult pain and the impact of pain on daily function (ie, functional disability) (33). Although developed for cancer pain, the BPI-SF has demonstrated sufficient reliability and validity with chronic nonmalignant pain (34). Respondents rate their pain intensity on the BPI-SF using an 11-point numerical rating scale with anchors of "no pain" and "pain as bad as you can imagine". Pain intensity values are obtained for its worst in the past $24 \mathrm{~h}$, its least in the past $24 \mathrm{~h}$, on average, and "right now" (35). In a manner similar to the two patient PPQ VAS scores, the BPI-SF pain score at its worst in the past $24 \mathrm{~h}$ was used in the present study. The BPI-SF also measures pain interference with seven daily activities in the past $24 \mathrm{~h}$, specifically, general activity, walking, work, mood, enjoyment of life, relations with others and sleep (33). Respondents rate each activity on an 11-point scale (from 0, "Does not interfere" to 10, "Completely interferes"). The BPI-SF pain interference value was scored as typically the mean of the seven interference items, with a scoring range of 0 to 10 (10). In the present study, parents completed both the pain intensity and pain interference components of BPI-SF on themselves.

\section{Statistical analyses}

Continuous variables were summarized using descriptive statistics (mean and SD, or median and interquartile range). Categorical variables were summarized using frequency counts and percentages. In addition to generating Q-Q plots, the Shapiro-Wilk test was applied to confirm the normality of the continuous variables and, thus, fitness for a parametric test statistic. Any continuous demographic or clinical outcome variable found to lack normality was reported and treated as nonparametric.

The agreement between the individual patient self-reported and parent proxy-reported PPQ scores and FDI scores were assessed using intraclass correlation coefficient (ICC) values $(36,37)$. Median group differences in these non-normally distributed PPQ scores and FDI scores were analyzed using the Wilcoxon signed-rank test. These comparative analyses were conducted for the total sample and separately for two patient age groups (eight to 12 years of age and 13 to 17 years of age).

Bland-Altman plots were used to evaluate any systematic tendency for parent proxy reports to overestimate or underestimate pain intensity and functional disability compared with patient self-reports. The mean patient-parent arithmetic difference (patient score minus parent score) was first calculated for the PPQ and the FDI (36). A BlandAltman plot was then generated for the paired patient-parent PPQ scores and patient-parent FDI scores to further assess their agreement $(38,39)$.

A simultaneous multivariable linear regression model was used to evaluate the association among the patient age (years), patient sex (female or male), patient race (African-American or Caucasian), duration of patient's pain (months), patient pain intensity (PPQ VAS score), parental pain intensity (BPI-SF pain score), and the observed difference between patient self-reported and parent proxy-reported PPQ scores. A stepwise regression method was used, with entry criterion of $\mathrm{P}<0.05$ and removal criterion of $\mathrm{P}>0.10$.

A simultaneous multivariable linear regression model was also used to evaluate the association between patient's age, sex, race, duration of pain, patient functional disability (patient FDI score), parental pain-related disability (BPI-SF pain interference score), and the observed difference between patient self-reported and parent proxyreported FDI scores. A stepwise regression method, with entry criterion of $\mathrm{P}<0.05$ and removal criterion of $\mathrm{P}>0.10$, was used.

The relationship between patient self-reported PPQ and FDI scores was assessed using Spearman's correlation coefficients, for the total sample and separately for the two patient age groups (eight to 12 years of age and 13 to 17 years of age).

For the correlations and group comparisons between the patient self-reported and the parent proxy-reported PPQ and FDI scores, as well as the unstandardized beta-coefficients from the fitted multivariable regression models, $\mathrm{P}<0.05$ was considered to be statistically significant. The conventional correlation values of 0.10 to $0.29=$ small (weak), 0.30 to $0.49=$ medium (moderate) and 0.50 to $1.0=$ large (strong) were applied (40), with a more rigorous a priori criterion (minimum) value of 0.50 required for adequate patient-parent concordance. All statistical analyses were performed using SPSS version 19.0 (IBM Corporation, USA). Bland-Altman plots were generated using MedCalc version 11.6.1.0 (MedCalc Software Inc, Belgium).

\section{RESULTS}

A total of 99 of the 145 (68\%) eligible patients and their accompanying parents were enrolled in the present study. The majority of the study participants in this sequential, convenience sample were female $(71 \%)$ and early adolescents (mean $[ \pm S D]$ age $13.2 \pm 2.4$ years). Eightyone per cent were Caucasian, 17\% African-American, 1\% Native American and $1 \%$ Asian. The enrolled patients presented with a variety of primary chronic pain conditions: headache (21\%); cervical, thoracic, lumbar and/or sacral spine pain (19\%); abdominal pain (18\%); extremity or large joint pain (18\%); fibromyalgia or a myofascial pain syndrome (15\%); or peripheral neuropathic pain (including complex regional pain syndrome types I and II) (8\%). All study patients had experienced their presenting pain condition for longer than one month (median duration 15 months, interquartile range seven to 36 months).

No data were collected on the reasons for study nonparticipation. However, the relatively low participation rate appeared to be due to frequently expressed parental time constraints and the already extensive evaluation performed on all new clinic patients. If both parents were available, one volunteered to serve as the sole study participant.

\section{Agreement between patient self-reported and parent proxy-reported} pain intensity

Agreement between individual PPQ pain scores: Table 2 presents the ICCs between the individual patient self-reported and the parent proxy-reported PPQ scores. The PPQ pain score agreement between patients and their parents met the a priori criterion (minimum) ICC value of 0.5 and was statistically significant $(\mathrm{P}<0.001)$ across the entire patient age range. The PPQ ICCs varied considerably between the two patient age strata (eight to 12 years of age and 13 to 17 years of age), with stronger agreement $(\mathrm{ICC}=0.75)$ observed in the older age group but no agreement ( $\mathrm{ICC}=0.15$ ) observed in the younger age group.

Agreement between group PPQ pain scores: Table 3 presents the group median patient self-reported and parent proxy-reported PPQ scores. At that group level, there was no statistically significant 


\section{TABLE 3}

Median patient self-reported and parent proxy-reported pain intensity scores on the Pediatric Pain Questionnaire and functional disability scores on the Functional Disability Index

\begin{tabular}{|c|c|c|c|}
\hline Scale & $\begin{array}{l}\text { Total sample } \\
\quad(n=99)\end{array}$ & $\begin{array}{c}8-12 \text { years of age } \\
(n=37)\end{array}$ & $\begin{array}{l}13-18 \text { years of age } \\
(n=62)\end{array}$ \\
\hline \multicolumn{4}{|c|}{ Pediatric Pain Questionnaire (0-100 visual analogue scale) } \\
\hline Patient & $85.0(72.0-97.0)^{*}$ & $83.0(55.0-97.5)^{\dagger}$ & $89.0(76.0$ \\
\hline Parent & $90.0(75.0-97.0)$ & $84.0(74.0-96.5)$ & 90. \\
\hline \multicolumn{4}{|c|}{ Functional Disability Inventory (0-60 score range) } \\
\hline Patient & $22.0(13.0-31.5)^{\S}$ & $20.0(9.0-30.0)^{\pi}$ & $23.0(15.0-35.5)^{\star \star}$ \\
\hline Parent & $25.0(12.8-33.0)$ & $22.0(9.0-30.0)$ & $29.0(17.0-33.5)$ \\
\hline
\end{tabular}

Numbers in parentheses represent the interquartile ranges for reported point estimates. ${ }^{*} P=0.40$ (patient versus parent); ${ }^{\dagger} P=0.22$ (patient versus parent); $\ddagger P=0.15$ (patient versus parent); $\S P=0.54$ (patient versus parent); $\mathbb{T} P=0.46$ (patient versus parent); ${ }^{* *} P=0.79$ (patient versus parent)

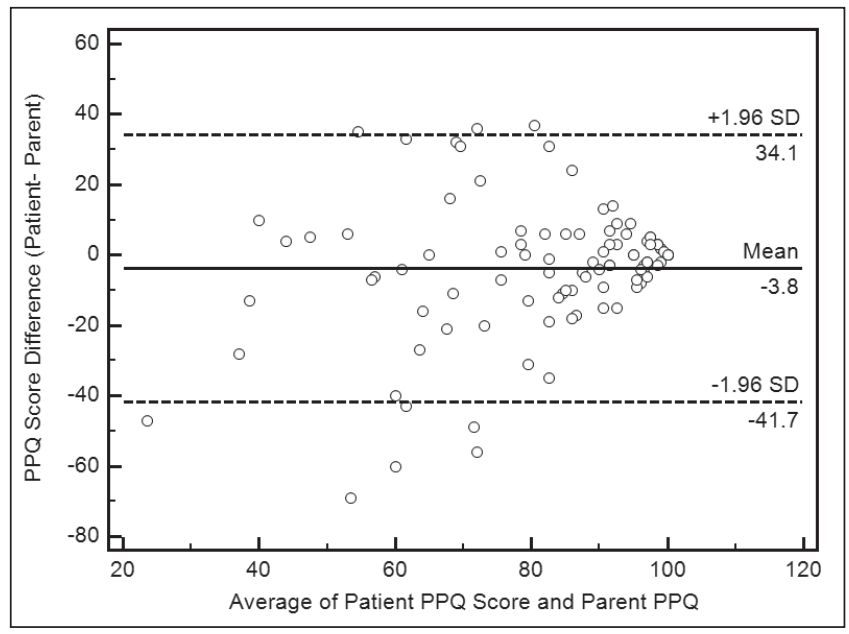

Figure 1) Bland-Altman plot for the Pediatric Pain Questionnaire (PPQ) scores

difference between patient self-reported and the parent proxyreported PPQ scores. The observed overall group median difference of 5.0 in the PPQ scores also did not appear to be clinically meaningful.

However, the Bland-Altman plot for the PPQ scores (Figure 1) revealed a considerable amount of variation and systematic bias in the parent-child dyad, with 95\% limits of agreement ranging from -34.4 to 35.2 (on the 100 -point PPQ pain scale), indicating a clinically significant inter-rater variability pattern across the entire graph (PPQ score range). However, there appeared to be greater parent-child agreement at greater pain intensity levels (average PPQ scores higher than approximately 80 of 100 ).

Predictors of patient-parent agreement about pain intensity Table 4 presents the results of the multivariable regression model for the relationship among the patient's age, sex, race, duration of pain, patient pain intensity (PPQ), parent pain intensity (BPI-SF) and dependent variable of the patient-parent agreement about the patient's pain intensity. There was a statistically significant association between the patient's self-reported pain intensity $(\beta=0.56, P<0.001)$ and the difference between the patient self-reported and parent proxy-reported pain intensity scores on the PPQ. The difference between the patient and parent PPQ scores increased by 0.56 points with each one-point increase in the patient's PPQ score.
TABLE 4

Regression coefficients for predictors of the congruence between patient self-reported and parent proxy-reported pain intensity scores and between patient self-reported and parent proxy-reported functional disability index (FDI) scores

\begin{tabular}{|c|c|c|c|c|}
\hline \multirow{3}{*}{$\begin{array}{l}\text { Independent } \\
\text { variable }\end{array}$} & \multicolumn{4}{|c|}{ Dependent variable } \\
\hline & \multicolumn{2}{|c|}{ PPQ pain score difference } & \multicolumn{2}{|c|}{$\begin{array}{l}\text { FDI functional disability } \\
\text { score difference }\end{array}$} \\
\hline & $\beta$ & $\mathbf{P}$ & $\beta$ & $\mathbf{P}$ \\
\hline Patient age, years & $0.20(-1.09,1.49)$ & 0.76 & $-0.11(-1.06,0.85)$ & 0.83 \\
\hline $\begin{array}{l}\text { Patient sex, } \\
\text { female/male }\end{array}$ & $-1.86(-8.83,5.11)$ & 0.60 & $-1.38(-6.48,3.73)$ & 0.59 \\
\hline $\begin{array}{l}\text { Patient race, } \\
\text { African-American/ } \\
\text { Caucasian }\end{array}$ & $2.44(-1.92,6.80)$ & 0.27 & $0.16(-2.89,3.20)$ & 0.92 \\
\hline $\begin{array}{l}\text { Patient's duration } \\
\text { of pain, months }\end{array}$ & $-0.003(-0.09,0.084)$ & 0.94 & $\begin{array}{c}-0.017(-0.082 \\
0.048)\end{array}$ & 0.60 \\
\hline Patient PPQ score & $0.56(0.41,0.71)$ & $<0.001$ & $\mathrm{~N} / \mathrm{A}$ & \\
\hline Patient FDI score & $\mathrm{N} / \mathrm{A}$ & & $0.50(0.31,0.69)$ & $<0.001$ \\
\hline $\begin{array}{l}\text { Parent BPI-SF } \\
\text { pain score }\end{array}$ & $-0.38(-1.41,0.65)$ & 0.46 & $\mathrm{~N} / \mathrm{A}$ & \\
\hline $\begin{array}{l}\text { Parent BPI-SF } \\
\text { interference score }\end{array}$ & N/A & & $-0.12(-0.96,0.71)$ & 0.77 \\
\hline
\end{tabular}

Numbers in parentheses represent $95 \%$ Cls for reported point estimates. Total sample, $n=97$. BPI-SF Brief Pain Inventory-Short Form; N/A Not applicable; $P P Q$ Pediatric Pain Questionnaire

Agreement between patient self-reported and parent proxyreported functional disability

Agreement between individual FDI scores: Table 2 presents the ICCs between the individual patient self-reported and the parent proxy-reported FDI scores. The FDI score agreement between patients and their parents met the a priori criterion (minimum) ICC value of 0.5 and was statistically significant $(P<0.001)$ across the entire patient age range. The FDI ICCs varied considerably between the two patient age strata (eight to 12 years of age and 13 to 17 years of age), with stronger agreement ( $\mathrm{ICC}=0.66)$ observed in the older patients.

Agreement between group FDI scores: Table 3 presents the group median patient self-reported and parent proxy-reported FDI scores. At the group level, there was no statistically significant difference between the patient self-reported and the parent proxy-reported FDI scores. The observed overall group median difference of 3.0 in the PPQ scores also did not appear to be clinically meaningful.

However, the Bland-Altman plot for the FDI scores (Figure 2) revealed a large but inconsistent amount of variation and systematic bias in the parent-child dyad, with $95 \%$ limits of agreement ranging from -24.0 to 22.8 (on the 60-point functional disability scale), indicating a clinically significant inter-rater variability pattern across the entire graph (FDI score range). Furthermore, no consistent pattern was observed within the FDI score range.

Predictors of patient-parent agreement with regard to functional disability

Table 4 presents the results of the multivariable regression model for the relationship among the patient's age, sex, race, duration of pain, patient functional disability, parental pain-related disability, and dependent variable of the patient-parent agreement with regard to the patient's functional disability on the FDI. There was a statistically significant association between the patient's self-reported functional disability $(\beta=0.50 ; \mathrm{P}<0.001)$ and the difference between the patient self-reported and parent proxy-reported disability scores on the FDI. The difference between the patient and parent FDI scores increased by 0.5 points with each one-point increase in the patient's FDI score. 


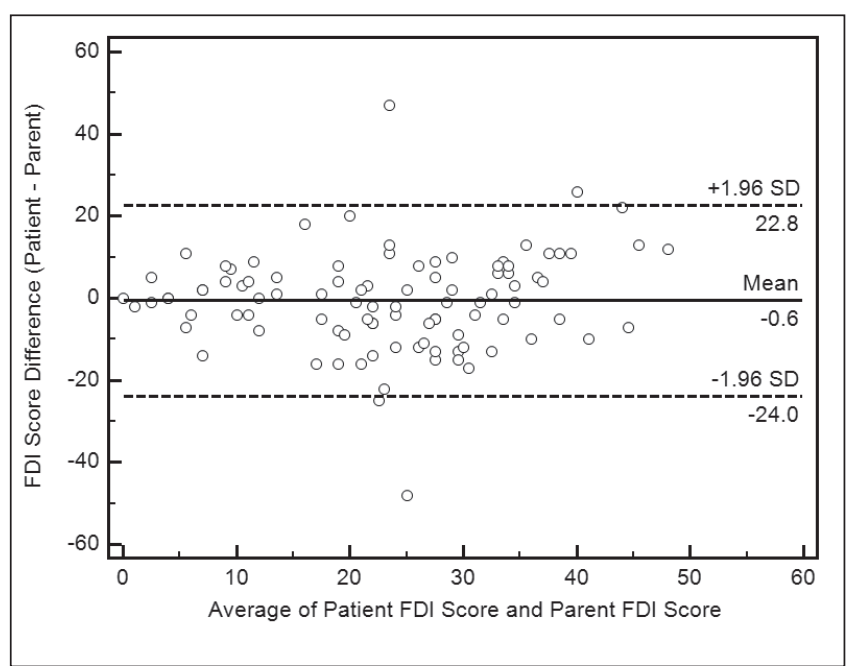

Figure 2) Bland-Altman plot for the Functional Disability Index (FDI) scores

Relationship between patient self-reported pain intensity and patient self-reported functional disability

Table 5 presents the Spearman's correlation coefficients between the enrolled patients' self-reported PPQ scores and their FDI scores. There was a moderately positive and statistically significant relationship between PPQ scores and FDI scores across the entire patient age range $(\mathrm{P}<0.001)$ and within the 13 to 17 years of age stratum $(\mathrm{P}<0.001)$ but not within the eight to 12 years of age stratum $(\mathrm{P}=0.27)$. However, none of these correlations achieved the a priori minimum (criterion) $\mathrm{r}$ value of 0.5 . Moreover, despite a very high group median selfreported pain intensity score of 85.0 (interquartile range 72.0 to 97.0 ), $24 \%$ of study patients reported 'no/minimal' disability, $43 \%$ 'moderate' disability and only $33 \%$ 'severe' disability, based on the above recently defined three-level classification system for the FDI (32).

\section{DISCUSSION}

In our sample of pediatric chronic pain patients, there was parent-child agreement at the individual level in adolescents (13 to 17 years of age), but not in younger children (eight to 12 years of age), regarding the patient's pain intensity. However, there were no overall or age-specific group differences between the paired patient self-reported and the parent proxy-reported PPQ scores. The difference between the paired patients' self-reported and parents' proxy-reported pain scores was significantly associated with greater patient pain intensity. Across the entire age range, there was parent-child agreement at the individual level regarding the patient's functional disability. There were also no overall or age-specific group differences between the paired patient selfreported and the parent proxy-reported FDI scores. The difference between the paired patients' self-reported and parents' proxy-reported disability scores was significantly associated with greater patient functional disability. There was a significant, but only moderately positive, relationship between our pediatric chronic pain patients' self-reported PPQ scores and their self-reported FDI scores in adolescents (13 to 17 years of age), but not in younger children (eight to 12 years of age). While equal merit should ideally be given to pediatric chronic pain patients' self-reports and their parents' proxy reports of pain intensity and disability, it would thus appear that, as needed, pediatric patients or parents can offer a clinically valid, single clinical perspective.

Previous studies of child versus parent perceptions of pediatric health status have applied various statistical methods, resulting in potentially artefactually conflicting results and conclusions (41-43). Specifically, child-parent agreement should ideally be assessed at the level of the individual according to ICC and at the level of the group according to comparison of means (or medians if the data are
TABLE 5

Correlations between patients' self-reported pain intensity and patients' self-reported functional disability

\begin{tabular}{lccc}
\hline & \multicolumn{3}{c}{ Spearman's correlation coefficients } \\
\cline { 2 - 4 } Scale & $\begin{array}{c}\text { Total sample } \\
(\mathbf{n}=\mathbf{9 7})\end{array}$ & $\begin{array}{c}\mathbf{8 - 1 2} \text { years of age } \\
(\mathbf{n}=\mathbf{3 7})\end{array}$ & $\begin{array}{c}13-18 \text { years of age } \\
(\mathbf{n}=60)\end{array}$ \\
\hline PPQ score versus & 0.38 & 0.19 & 0.47 \\
FDI score & $(0.20-0.54)^{*}$ & $(-0.14-0.48)^{\dagger}$ & $(0.24-0.64)^{*}$ \\
\hline
\end{tabular}

Numbers in parentheses represent 95\% Cls for reported point estimates. ${ }^{*} P<0.001 ;{ }^{t} P=0.27$. FDI Functional Disability Inventory; $P P Q$ Pediatric Pain Questionnaire (0-100 $\mathrm{mm}$ visual analogue scale)

nonparametric) (44-46). With a paired data set with two variables that measure the same construct (eg, functional disability), rather than two different constructs for a single individual (eg, pain intensity and functional disability), the ICC is a more appropriate measure of agreement than the more frequently applied Pearson's or Spearman's correlation $(47,48)$.

Furthermore, Bland and Altman $(38,39)$ have argued that when looking for agreement between clinical measurement methods, calculating the Pearson's (or Spearman's) correlation coefficient could produce erroneous results because it measures the strength of the relationship and not the level of agreement, and it does not take into consideration systematic error $(43,49)$. Likewise, a change in the scale of measurement would not affect the correlation but could have a significant effect on the level of agreement. Similarly, using a paired $t$ test (or Wilcoxon signed-rank test) to compare the child-parent responses may detect differences but would not identify the variability or the systematic error $(38,39,43,49)$. Additional insight into the pattern of agreement between child self-reported and parent proxy-reported health status can thus be provided by a Bland-Altman plot (43). For completeness and comparison purposes, all three methods of assessing child-parent agreement were thus applied here to analyze our data collected using the PPQ and FDI instruments.

In patients referred to a pediatric gastroenterology clinic for evaluation of chronic abdominal pain, Pearson's correlation coefficients between child and parent reports on the FDI were significant for girls $(\mathrm{r}=0.31)$ and for boys $(\mathrm{r}=0.32)$. The agreement between child and parent reports on the FDI was stronger at 12 to 17 years of age $(r=0.50)$ compared with eight to 11 years of age $(r=0.21)$ (23). In our more diverse pediatric chronic pain sample, we observed higher ICC values but a similar stronger correlation in older patients. This age-related difference may reflect more robust communication between adolescents and their parents, and possibly their health care providers. This would suggest that younger pediatric chronic pain patients require additional efforts by their parents and treating clinicians to have their functional limitations well understood.

Unlike in children with juvenile idiopathic arthritis, in whom Bland-Altman plots have revealed good parent-child (and good physician-child) agreement at the lowest levels of pain intensity and increasing disagreement with increasing pain intensity $(50,51)$, we observed better parent-child agreement at higher levels of pain intensity (average PPQ scores higher than approximately 80 of 100). We observed neither such pattern of agreement in the Bland-Altman plot of FDI scores. This may indicate that children are more able or more likely to communicate their chronic pain intensity - especially when it is severe - than their functional disability level to their parents and treating clinicians. If so, then particular attention should be devoted by the parent and clinician to eliciting and endorsing the pediatric patient's own perspective on the adverse functional effects of their chronic pain.

However, based on a regression model, we observed that the difference between patients' self-reported and parents' proxy-reported PPQ scores was significantly associated only with greater intensity of the child's pain. A large-scale German population study of chronic 
headache assessed the agreement between child and parent reports regarding various domains of pediatric health (52). Of note, as in our present outpatient clinic sample, patient age, sex and a history of parental pain (headache) were not associated with the observed differences between child and parent reports about pediatric headache frequency, duration and intensity in this general population cohort (52). These collective findings do not support a significant degree of parental enmeshment, pain behaviour modelling and perpetuation of a 'family sickness model' between parents and their children with chronic pain.

The CALI is another instrument designed to assess functional impairment due to chronic pain in school-age children $(7,25)$. In the initial pilot study of the CALI in children with recurrent pain, a significant correlation was observed between patients' selfreported pain intensity scores and their FDI scores ( $r=0.43)(7)$. A significant correlation was also observed between children's selfreported pain intensity scores and their CALI-21 scores $(r=0.42)$ (24). In the subsequent development and validation of the Child Activity Limitations Questionnaire (the paper-and-pencil, selfreport version of the CALI), a significant correlation was observed between patient self-reported pain intensity and Child Activity Limitations Questionnaire scores $(r=0.37)$. While we observed comparable and statistically significant correlations between pain intensity and functional disability overall $(r=0.38)$ and in older patients $(r=0.47)$, our present correlation was very low and not significant in younger patients $(r=0.19)$. None of these reported correlations met an a priori minimum (cut-point) of 0.5 , suggesting that, at least in routine clinical practice, pediatric pain medicine practitioners should continue to focus on improvement in daily function with patients and their parents (on a case-by-case basis), with less emphasis, perhaps, being placed on immediate pain intensity reduction or its ultimate elimination.

In a sample of children and adolescents with chronic pain conditions being evaluated in a pediatric pain management clinic, significant correlations were observed between child and parent reports for the total CALI score $(r=0.73$; ICC=0.73) (24). Despite a similarly diverse sample of chronic pain diagnoses, this overall child-parent ICC value with the CALI was stronger than the overall ICC of 0.57 we observed with the FDI. As noted by Palermo et al $(7,24)$, the CALI may, thus, be a better chronic pain measure than the FDI, except perhaps for functional abdominal pain.

Finally, children with chronic pain often interact with numerous health care professionals during their search to understand and to ameliorate their pain. Moreover, these interactions with health care professionals can have a tremendous and sustained influence on children's perceptions and chronic pain experiences. Using semistructured interviews, a qualitative study sought to understand the experiences of children with chronic pain as they interacted with health care professionals (19). In the majority of these clinical interactions, children reported feeling misunderstood, disbelieved and abandoned ("If they can't see it, it's not there" and "They don't believe me") (19). These findings demonstrated that children's experiences with professionals influence their approach toward current and future health care encounters - often resulting in guarded relationships with their health care providers. Children also developed negative perceptions about their pain, in particular perceiving that their chronic pain was life-threatening ("I must be dying") and required major life adjustments ("Pain is something that can't be cured...I [will] have this for the rest of my life") (19). This phenomenon may underlie the persistence of pediatric chronic pain conditions into adulthood (53-56). Thus, to optimally understand and care for children and adolescents with chronic pain, it is essential that health care professionals provide such youth with an equal and bona fide opportunity to communicate their unique experiences with pain $(19,57)$. The present findings support the need for such a highly individualized approach to pediatric chronic pain assessment and treatment.

\section{Limitations}

In the setting of chronic pain, parents and children may develop a shared narrative that is often repeatedly rehearsed in their successive medical encounters. In particular, this would include ratings of pain intensity and functional disability. In a general community sample (52), fewer parent-child dyads may have occasion to reach such agreement. If a child with chronic pain and his or her parent agree on pain intensity or disability, it may indicate that both measures are valid; or, alternatively, that they have implicitly or explicitly agreed on a joint presentation of the situation. While our study patients and their parents were specifically instructed to complete all of the study questionnaires independently, they were not placed in separate rooms. Thus, there may have been further informant cross-contamination.

Based on previous published recommendations $(41,44,46)$, we had planned a priori to include the category of the parental study participant/respondent (mother versus father) as a variable in our regression model. However, only six $(6.1 \%)$ of the presently enrolled parental study participants and survey respondents were the patient's father, a number too small to enable a valid assessment of the effect of the parental respondent in patient-parent agreement.

Further limitations to our study include the relatively small sample size; however, it was comparable with that of other published pediatric chronic pain patient samples. A similar demographic and clinical profile has been observed during the past decade among patients referred to four other tertiary-care, multidisciplinary pediatric pain medicine clinics in the United States (4,58-60). In contrast, the present sample included a greater percentage of African-Americans, reflecting the demographics of the catchment area of our children's hospital. Despite this greater percentage of African-American participants, minorities (especially ethnic Hispanics or Latinos) were under-represented in the present study, reducing the external validity of its findings.

\section{CONCLUSION}

Based on the present and previous samples of patients, there may be a lack of complete agreement within the parent-child dyad regarding pain intensity and functional disability. Awareness of these patterns of concordance and discordance should help clinicians in interpreting and applying parent proxy reports versus pediatric patient self-reports of chronic pain intensity and related dysfunction (8). Parents' proxy reports should not be viewed as a primary substitute for children's selfreports in pediatric pain and health assessment. While each offers an important and valid perspective on the pediatric pain experience, children and adolescents successfully communicating an appraisal of their own chronic pain and its adverse personal impact can be vitally therapeutic $(19,52)$.

\section{SUMMARY}

There may be disagreement within the parent-child dyad with regard to a patient's chronic pain intensity and related functional disability. The PPQ and FDI were completed by a pediatric pain medicine clinic sample. There was adequate parent-child agreement at the individual and group level regarding the patient's pain intensity and functional disability. However, Bland-Altman plots revealed considerable interrater variation in the PPQ and FDI across their score ranges. While equal merit should ideally be given to the patient's and parent's perceptions of pediatric chronic pain, if necessary, either can offer a suitably valid single clinical perspective.

ACKNOWLEDGEMENTS: The authors thank Ms Debbie Owen for her invaluable contribution in scoring the study instruments, collating the study data and managing the study database.

FUNDING: Maurice S Albin Endowed Professorship in Anesthesiology. 


\section{REFERENCES}

1. Gold JI, Yetwin AK, Mahrer NE, et al. Pediatric chronic pain and health-related quality of life. J Pediatr Nurs 2009;24:141-50.

2. Jordan AL, Eccleston C, Osborn M. Being a parent of the adolescent with complex chronic pain: An interpretative phenomenological analysis. Eur J Pain 2007;11:49-56.

3. Slover R, Neuenkirchen GL, Olamikan S, Kent S. Chronic pediatric pain. Adv Pediatr 2010;57:141-62.

4. Vetter TR. A clinical profile of a cohort of patients referred to an anesthesiology-based pediatric chronic pain medicine program. Anesth Analg 2008;106:786-94.

5. Jastrowski Mano KE, Khan KA, Ladwig RJ, Weisman SJ. The impact of pediatric chronic pain on parents' health-related quality of life and family functioning: Reliability and validity of the PedsQL 4.0 Family Impact Module. J Pediatr Psychol 2011;36:517-27.

6. Palermo TM. Impact of recurrent and chronic pain on child and family daily functioning: A critical review of the literature. J Dev Behav Pediatr 2000;21:58-69.

7. Palermo TM, Witherspoon D, Valenzuela D, Drotar DD. Development and validation of the Child Activity Limitations Interview: A measure of pain-related functional impairment in school-age children and adolescents. Pain 2004;109:461-70.

8. Cohen LL, Vowles KE, Eccleston C. Adolescent chronic pain-related functioning: Concordance and discordance of mother-proxy and self-report ratings. Eur J Pain 2010;14:882-6.

9. Vetter TR. Assessment tools in pediatric chronic pain: Reliability and validity. In: McClain BC, Suresh S, eds. Handbook of Pediatric Chronic Pain: Current Science and Integrative Practice. New York: Springer, 2011:63-85.

10. Huguet A, Stinson JN, McGrath PJ. Measurement of self-reported pain intensity in children and adolescents. J Psychosom Res 2010;68:329-36.

11. Walker LS, Greene JW. The functional disability inventory: Measuring a neglected dimension of child health status. J Pediatr Psychol 1991;16:39-58.

12. Walco GA, Rozelman H, Maroof DA. The Assessment and Management of Chronic and Recurrent Pain in Adolescents. In: O'Donohue WT, ed. Behavioral Approaches to Chronic Disease in Adolescence. New York: Springer, 2009:163-75.

13. Palermo TM, Chambers CT. Parent and family factors in pediatric chronic pain and disability: An integrative approach. Pain 2005;119:1-4.

14. Varni JW, Rapoff MA, Waldron SA, Gragg RA, Bernstein BH, Lindsley CB. Effects of perceived stress on pediatric chronic pain. J Behav Med 1996;19:515-28.

15. Hoftun GB Romundstad PR, Rygg M. Association of parental chronic pain with chronic pain in the adolescent and young adult: Family linkage data from the hunt study. Arch Pediatr Adolesc Med 2012:1-9.

16. Saunders K, Korff MV, Leresche L, Mancl L. Relationship of common pain conditions in mothers and children. Clin J Pain 2007;23:204-13.

17. Laurell K, Larsson B, Eeg-Olofsson O. Headache in schoolchildren: Association with other pain, family history and psychosocial factors. Pain 2005;119:150-8.

18. Campo JV, Bridge J, Lucas A, et al. Physical and emotional health of mothers of youth with functional abdominal pain. Arch Pediatr Adolesc Med 2007;161:131-7.

19. Dell'Api M, Rennick JE, Rosmus C. Childhood chronic pain and health care professional interactions: Shaping the chronic pain experiences of children. J Child Health Care 2007;11:269-86.

20. Schor EL. Family pediatrics: Report of the Task Force on the Family. Pediatrics 2003;111:1541-71.

21. Reid K, Lander J, Scott S, Dick B. What do the parents of children who have chronic pain expect from their first visit to a pediatric chronic pain clinic? Pain Res Manag 2010;15:158-62.

22. Long AC, Guite JW. Treatment-related expectations in pediatric chronic pain. In: von Bayer CL, ed. Pediatric Pain Letter: Commentaries on Pain in Infants, Children, and Adolescents, 2008.

23. Claar RL, Walker LS. Functional assessment of pediatric pain patients: Psychometric properties of the functional disability inventory. Pain 2006;121:77-84.

24. Palermo TM, Lewandowski AS, Long AC, Burant CJ. Validation of a self-report questionnaire version of the Child Activity Limitations Interview (CALI): The CALI-21. Pain 2008;139:644-52.
25. Hainsworth KR, Davies WH, Khan KA, Weisman SJ. Development and preliminary validation of the child activity limitations questionnaire: Flexible and efficient assessment of pain-related functional disability. J Pain 2007;8:746-52.

26. U.S. Census Bureau. State \& County QuickFacts: Alabama, 2009.

27. Varni JW, Rapoff MA, Waldron SA, Gragg RA, Bernstein BH, Lindsley CB. Chronic pain and emotional distress in children and adolescents. J Dev Behav Pediatr 1996;17:154-61.

28. Cohen LL, Lemanek K, Blount RL, et al. Evidence-based Assessment of Pediatric Pain. J Pediatr Psychol 2008;33:939-55.

29. Rapoff MA. Pediatric measures of pain: The Pain Behavior Observation Method, Pain Coping Questionnaire (PCQ), and Pediatric Pain Questionnaire. Arthritis Rheum 2003;49:S90-S5.

30. Zhou H, Roberts P, Horgan L. Association between self-report pain ratings of child and parent, child and nurse and parent and nurse dyads: Meta-analysis. J Adv Nurs 2008;63:334-42.

31. Palermo TM, Long AC, Lewandowski AS, Drotar D, Quittner AL, Walker LS. Evidence-based assessment of health-related quality of life and functional impairment in pediatric psychology. J Pediatr Psychol 2008;33:983-96.

32. Kashikar-Zuck S, Flowers SR, Claar RL, et al. Clinical utility and validity of the Functional Disability Inventory among a multicenter sample of youth with chronic pain. Pain 2011;152:1600-7.

33. Cleeland CS. Measurement of pain by subjective report. In: Chapman CR, Loeser JD, eds. Issues in Pain Measurement. New York: Raven Press, 1989:391-403.

34. Tan G, Jensen MP, Thornby JI, Shanti BF. Validation of the Brief Pain Inventory for chronic nonmalignant pain. J Pain 2004;5:133-7.

35. Cleeland C. The Brief Pain Inventory User Guide. Houston: MD Anderson Cancer Center, 2009.

36. Lee J, Koh D, Ong CN. Statistical evaluation of agreement between two methods for measuring a quantitative variable. Comput Biol Med 1989;19:61-70.

37. McGraw KO, Wong SP. Forming inferences about some intraclass correlation coefficients. Psychological Methods 1996;1:30-46.

38. Bland JM, Altman DG. Statistical methods for assessing agreement between two methods of clinical measurement. Lancet 1986;1:307-10.

39. Bland JM, Altman DG. Measuring agreement in method comparison studies. Stat Methods Med Res 1999;8:135-60.

40. Cohen J. Statistical Power Analysis for the Behavioral Science, 2nd edn. Hillsdale, New Jersey: Lawrence Erlbaum Associates, 1988.

41. Cremeens J, Eiser C, Blades M. Factors influencing agreement between child self-report and parent proxy-reports on the Pediatric Quality of Life Inventory 4.0 (PedsQL) generic core scales. Health Qual Life Outcomes 2006;4:58.

42. Vetter TR, Bridgewater CL, McGwin G Jr. An observational study of patient versus parental perceptions of health-related quality of life in children and adolescents with a chronic pain condition: Who should the clinician believe? Health Qual Life Outcomes 2012;10:85.

43. Taylor RM, Grieve A, Gibson F, Dhawan A, Franck LS. Parental assessment of adolescent quality of life: Can it replace self-assessment? Qual Life Res 2011;20:1715-20.

44. Upton P, Lawford J, Eiser C. Parent-child agreement across child health-related quality of life instruments: A review of the literature. Qual Life Res 2008;17:895-913.

45. Sneeuw KC, Sprangers MA, Aaronson NK. The role of health care providers and significant others in evaluating the quality of life of patients with chronic disease. J Clin Epidemiol 2002;55:1130-43.

46. Eiser C, Morse R. Can parents rate their child's health-related quality of life? Results of a systematic review. Qual Life Res 2001; 10:347-57.

47. de Vet HCW, Terwee CB, Knol DL, Bouter LM. When to use agreement versus reliability measures. J Clin Epidemiol 2006;59:1033-9.

48. Bruton A, Conway JH, Holgate ST. Reliability: What is it, and how is it measured? Physiotherapy 2000;86:94-9.

49. Altman DG. Practical Statistics for Medical Research. London: Chapman \& Hall, 1991.

50. Garcia-Munitis P, Bandeira M, Pistorio A, et al. Level of agreement between children, parents, and physicians in rating pain intensity in juvenile idiopathic arthritis. Arthritis Care Res 2006;55:177-83.

51. Lal SD, McDonagh J, Baildam E, et al. Agreement between proxy and adolescent assessment of disability, pain, and well-being in juvenile idiopathic arthritis. J Pediatr 2011;158:307-12. 
52. Kroner-Herwig B, Morris L, Heinrich M, Gassmann J, Vath N. Agreement of parents and children on characteristics of pediatric headache, other pains, somatic symptoms, and depressive symptoms in an epidemiologic study. Clin J Pain 2009;25:58-64.

53. Vetter TR. The epidemiology of pediatric chronic pain. In: McClain BC, Suresh S, eds. Handbook of Pediatric Chronic Pain: Current Science and Integrative Practice. New York: Springer, 2011:1-14.

54. Fearon P, Hotopf M. Relation between headache in childhood and physical and psychiatric symptoms in adulthood: National birth cohort study. BMJ 2001;322:1145.

55. Hotopf M, Carr S, Mayou R, Wadsworth M, Wessely S. Why do children have chronic abdominal pain, and what happens to them when they grow up? Population based cohort study. BMJ 1998;316:1196-200.
56. Brattberg G. Do pain problems in young school children persist into early adulthood? A 13-year follow-up. Eur J Pain 2004;8:187-99.

57. Clemente I. Progressivity and participation: Children's management of parental assistance in paediatric chronic pain encounters. Sociol Health Illn 2009;31:872-8.

58. Eccleston C, Crombez G, Scotford A, Clinch J, Connell H. Adolescent chronic pain: Patterns and predictors of emotional distress in adolescents with chronic pain and their parents. Pain 2004;108:221-9.

59. Kashikar-Zuck S, Goldschneider KR, Powers SW, Vaught MH, Hershey AD. Depression and functional disability in chronic pediatric pain. Clin J Pain 2001;17:341-9.

60. Logan DE, Simons LE, Kaczynski KJ. School functioning in adolescents with chronic pain: The role of depressive symptoms in school impairment. J Pediatr Psychol 2009;34:882-92. 


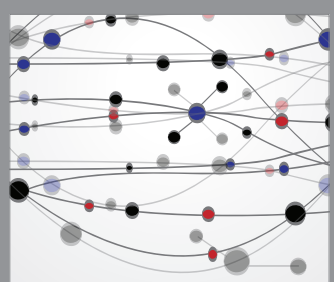

The Scientific World Journal
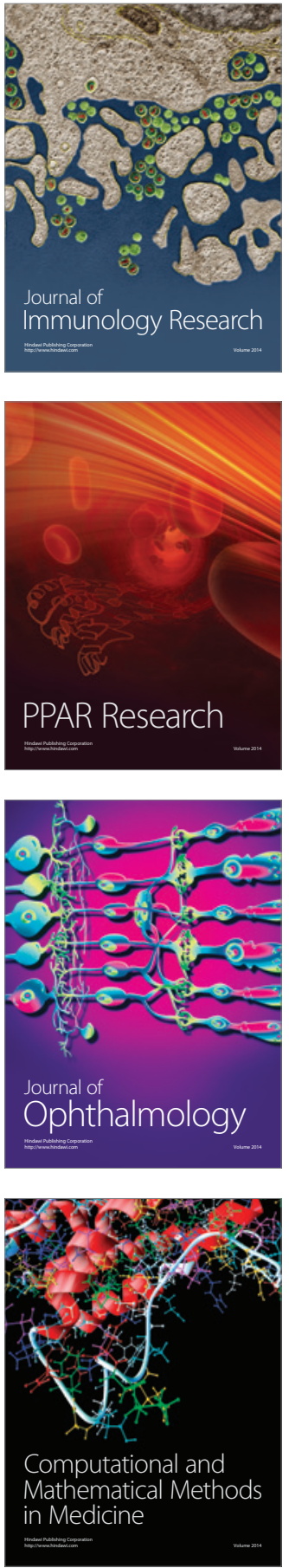

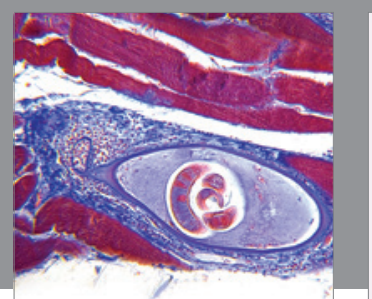

Gastroenterology Research and Practice

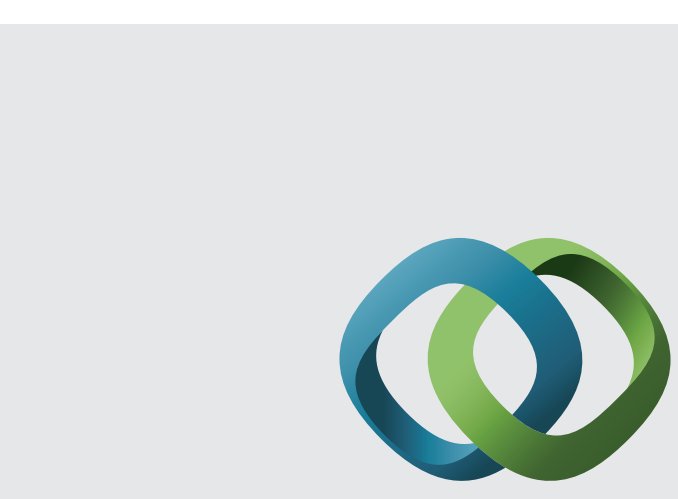

\section{Hindawi}

Submit your manuscripts at

http://www.hindawi.com
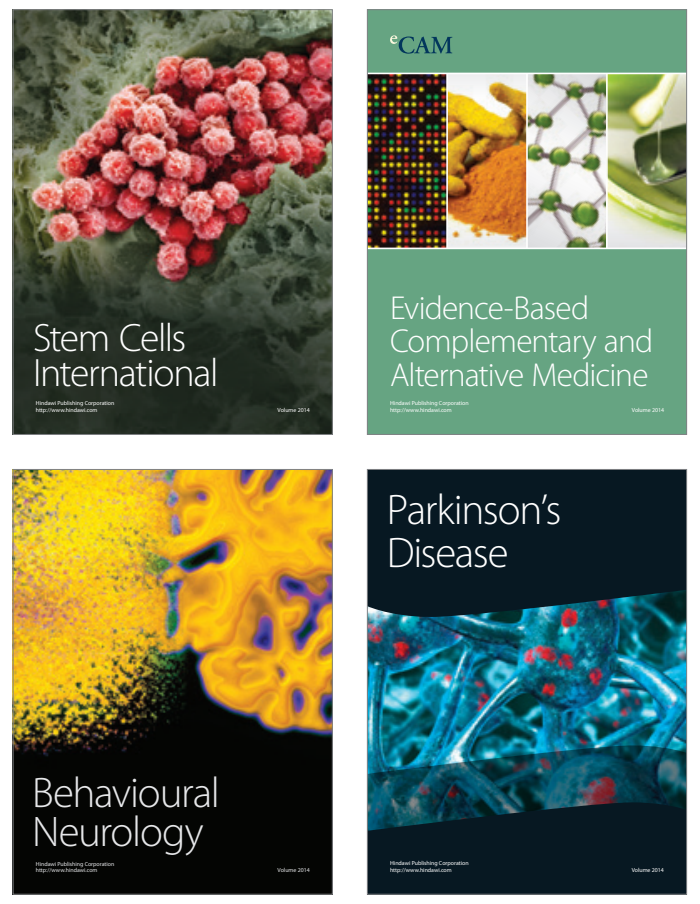
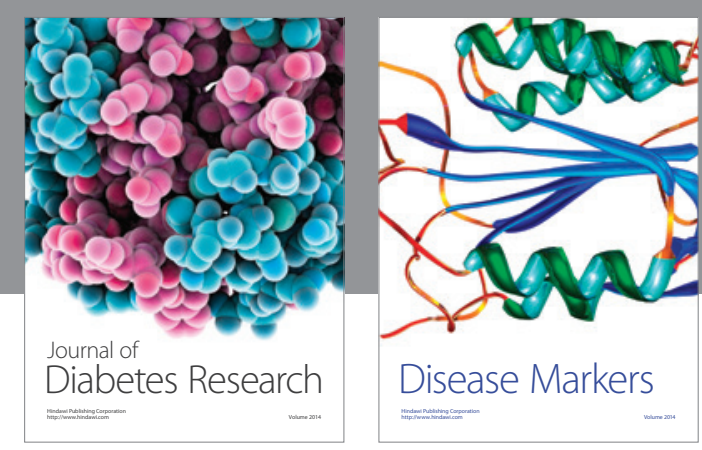

Disease Markers
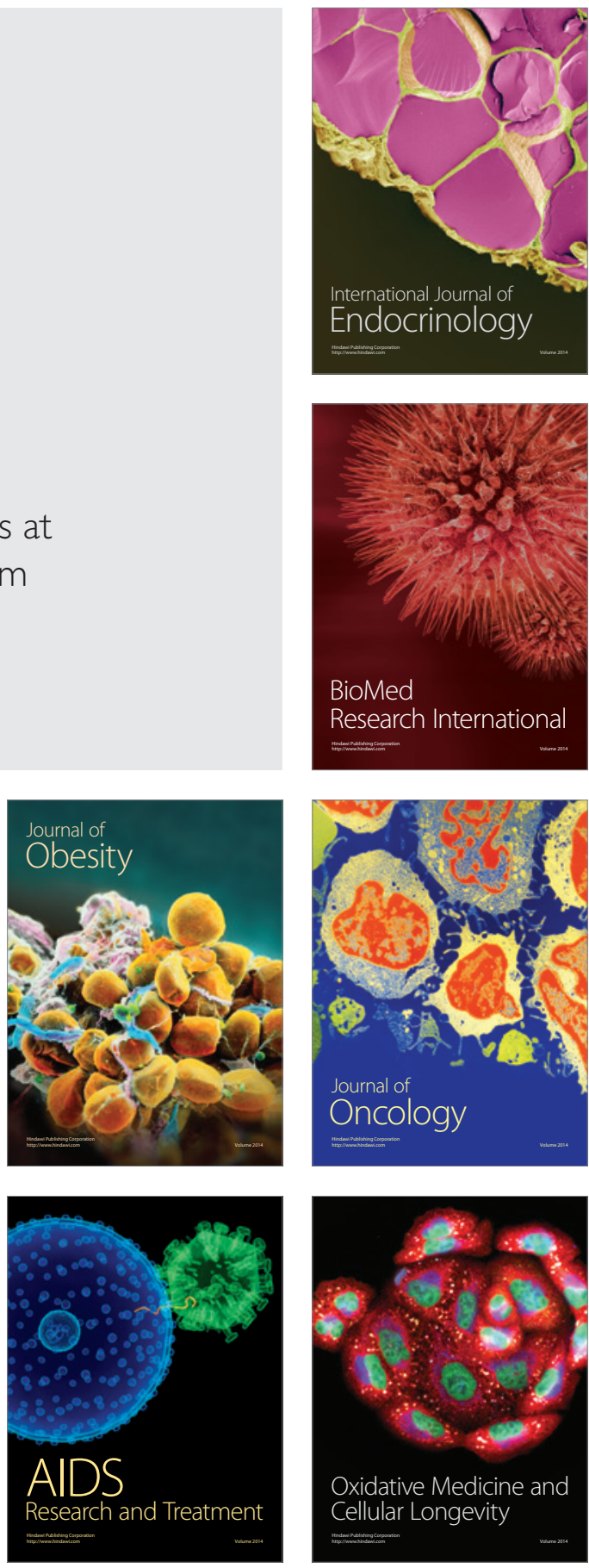